\begin{abstract}
Iranica
Abstracta Iranica Revue bibliographique pour le domaine irano-aryen

Volume 34-35-36 | 2017

Comptes rendus des publications de 2011-2013
\end{abstract}

\title{
Andreas Fuchs. Das Osttigrisgebiet von Agum II. bis zu Darius I. (ca. 1500 bis 500 v. Chr.)
}

\section{Astrid Nunn}

\section{(2) OpenEdition}

1 Journals

\section{Édition électronique}

URL : http://journals.openedition.org/abstractairanica/41435

DOI : 10.4000/abstractairanica.41435

ISSN : 1961-960X

Éditeur :

CNRS (UMR 7528 Mondes iraniens et indiens), Éditions de l'IFRI

\section{Référence électronique}

Astrid Nunn, "Andreas Fuchs. Das Osttigrisgebiet von Agum II. bis zu Darius I. (ca. 1500 bis 500 v. Chr.)», Abstracta Iranica [En ligne], Volume 34-35-36 | 2017, document 8, mis en ligne le 15 juillet 2016, consulté le 30 septembre 2020. URL : http://journals.openedition.org/abstractairanica/41435; DOI : https://doi.org/10.4000/abstractairanica.41435

Ce document a été généré automatiquement le 30 septembre 2020.

Tous droits réservés 


\title{
Andreas Fuchs. Das Osttigrisgebiet von Agum II. bis zu Darius I. (ca. 1500 bis 500 v. Chr.)
}

\author{
Astrid Nunn
}

\section{RÉFÉRENCE}

Andreas Fuchs. « Das Osttigrisgebiet von Agum II. bis zu Darius I. (ca. 1500 bis 500 v. Chr.) », in : Peter Miglus, Simone Mühl, eds., Between the Cultures. The Central Tigris Region from the $3^{\text {rd }}$ to the $1^{\text {st }}$ Millennium BC. Heidelberg, 2011, p. 229-320.

1 Cet article a paru dans une monographie qui est le résultat d'un symposium organisé sur la région du Tigre oriental par «L'Institut für Ur- und Frühgeschichte und Vorderasiatische Archäologie » à Heidelberg (Allemagne). Cette région englobe le territoire situé entre le Tigre et les monts du Zagros. Au nord elle est délimitée par le Grand Zab, au sud par la chaîne du Hamrin. La raison de cette mise à jour est la reprise de la recherche archéologique internationale dans le nord de l'Irak, seule région irakienne assez sûre pour s'y rendre.

2 L'unique communication mentionnant l'époque achéménide est celle d'Andreas Fuchs. À l'époque assyrienne et achéménide cette région était un pont entre l'Assyrie, la Babylonie, l'Elam et l'Iran de l'ouest. En tant que philologue, l'A. rassemble les sources écrites sur cette région et en tire des conclusions historiques. Cette région a été conquise par Cyrus II en 539 av. J.-C. La conquête sur les Babyloniens aura été facile et rapide, Cyrus profitera du manque de résistance de la population, qui ne prendra pas non plus partie contre Darius Ier. Cette région restera une terre de passage, mais elle perdra son importance stratégique au sein de l'Empire achéménide. 


\section{AUTEURS}

\section{ASTRID NUNN}

Université de Munich 